\title{
RESENHAS
}

\section{"El Proceso" e Igreja Católica na Argentina: entre a cruz e a espada}

\author{
Jessie Jane Vieira de Souza
}

VERBITSKY, Horacio. El silencio - de Paulo VI a Bergoglio - las relaciones secretas de la Iglesia con la ESMA. Buenos Aires: Editorial Sudamerica, 2005, 253pp.

OBREGON, Martín. Entre la cruz y la espada: la Iglesia católica durante los primeros años del "Proceso". Bernal: Universidad de Quilmes, 2005, 192pp.

O cardeal Antonio Caggiano, homem-chave da Igreja Católica argentina durante a metade do século XX, em 1961, na inauguração do primeiro curso interamericano de guerra contra-revolucionária e na presença do presidente Arturo Frondizi, afirmava:

(...) cuando la existencia de la iglesia se ve amenazada, deja de estar sujeta a los mandamientos de la moral. Cuando la unidad es el fin, todos los medios están san- tificados: enganos, traición, violencias, simonía, prisión y muerte. Porque el orden es para el bien de la comunidad, y el individuo debe ser sacrificado al bien común.

Convém assinalar que este curso contava com o assessoramento dos coronéis franceses Robert Bentresque e Jean Nougués e entre seus professores estavam alguns intelectuais argentinos, além de Victorio Bonamín, adjunto do cardeal Caggiano no Vicariato General Castrense. Todos estes franceses estiveram envolvidos com a guerra da Argélia e a violência que marcou a repressão sobre os rebeldes argelinos.

A presença de importantes nomes da Igreja Católica argentina em situações deste tipo nunca foi exatamente uma novidade, mas o que tem sido desvendado sobre a participação de parte significativa do episcopado daquele país, no proces- 
so de repressão desencadeada durante o chamado El Processo, tem ultrapassado todas as expectativas.

Em 2005 durante o processo de sucessão do papa João Paulo II, uma das 'novidades' era a possibilidade de tal escolha recair sobre um bispo latino-americano ou, mais precisamente, sobre o cardeal primaz da Argentina, dom Jorge Mario Bergoglio, feito cardeal, o décimo da história argentina, pelo papa João Paulo II em fevereiro de 2001.

Naquela ocasião, ainda que timidamente, toda a mídia mundial divulgou as denúncias feitas por entidades de direitos humanos daquele país, que afirmavam a vinculação do cardeal com o aparato repressivo montado na Argentina durante o chamado 'El Processo', isto é, com a feroz ditadura militar instalada em 1976.

Tais denúncias, no entanto, não ficaram restritas às veiculadas pelos defensores dos direitos humanos, pois já haviam se tornado objetos de pesquisas históricas realizadas por dois estudiosos argentinos e publicadas, em forma de livros, naquele mesmo período. É certo que anteriormente já havia surgido na Argentina um trabalho memorialista que tratava do tema, e que teve imensa repercussão no mercado edi- torial daquele país. Trata-se do livro de Emilio Mignone, publicado em 1986 (MIGNONE, Emilio. Iglesia y dictadura. Buenos Aires: Ediciones del Pensamiento Nacional), que traz uma grave denúncia a respeito da articulação do episcopado argentino com setores das Forças Armadas argentinas responsáveis pela execução da política repressiva adotada pelo Estado argentino naquele período histórico.

Mignone denunciava particularmente a participação do episcopado na repressão a católicos-leigos e clérigos envolvidos com a militância pastoral e, especialmente, o seqüestro e assassinato de sua filha, Mônica Candelária Mignone, de 24 anos, psicopedagoga e militante católica seqüestrada no dia 14 de maio de 1976, juntamente com outras quatro jovens catequistas que trabalhavam na comunidade de Vila Belén, no bairro de Bajo Flores.

Nesta resenha me refiro especificamente aos livros de Martín Obregon e de Horacio Verbitsky, que resultam de grande pesquisa documental e bibliográfica. Martín Obregon é historiador, professor e investigador da Faculdad de Humanidades y Ciências de la Educación de la Universidad Nacional de la Plata-UNLP, e tem apresentado tra- 
balhos sobre o papel da Igreja Católica em diferentes congressos e jornadas, tanto na Argentina quanto no exterior.

Verbitsky é um importante colunista do diário argentino Página 12, presidente do Centro de Estúdios Legales y Sociales - CELS , integra o Conselho Redator da Fundación Nuevo Periodismo Interamericano, presidido por Gabriel Garcia Marquez, a direção da organização Human Rights Watch e do Consorcio Internacional de Periodismo de Investigación. Tem dedicado sua vida profissional à cobertura da agenda política argentina, abordando temas como: corrupção, manipulação política do sistema judiciário, responsabilidade dos militares durante a chamada 'guerra suja' e responsabilidade da Igreja Católica no imenso passivo deixado pela ditadura.

Seus livros tratam do mesmo tema, mas ambos constróem suas narrativas partindo de pressupostos diferentes, já que o olhar lançado sobre o mesmo objeto parte de premissas diferentes. De um lado, um historiador tentando problematizar a história política da Igreja argentina vista como instituição historicamente conservadora e alinhada com as posições ultramontanas e integris- tas; de outro, um jornalista preocupado em levar à opinião pública a biografia política desta instituição que ainda hoje tenta desempenhar certo protagonismo político, como é o caso do recente debate sobre o aborto.

Obregon busca entender os vínculos existentes entre a Igreja Católica e o aparato repressivo argentino, tomando por base as relações estabelecidas pela Igreja com o Estado e a sociedade ao longo da história argentina e, mais precisamente, ao longo do século XX.

No primeiro capítulo, ele parte das relaçôes da história da Igreja Católica argentina entre o Vaticano II e a ditadura militar dos anos de 1965 a 1976. Nesta análise o autor trata do impacto das diretrizes advindas do Concilio Vaticano II sobre a Igreja - como o campo católico se mobilizou a favor ou contra as reformas propostas; os cenários dos debates ocorridos a partir das interpretações dos textos sagrados, do papel do magistério católico, da liturgia e da ação pastoral; a relação entre o episcopado católico entre Medellín e o chamado 'El Processo'.

Obregon caracteriza ainda que de forma sistemática, os diferentes posicionamentos existentes dentro 
do episcopado, a fim de evidenciar a complexidade das relações estabelecidas com o Estado e a sociedade, e como, nesta dinâmica, se deu o rompimento entre a 'Igreja del pueblo' e a ofensiva golpista do tradicionalismo católico.

A partir do terceiro capítulo o autor se detém mais especificamente no posicionamento da Igreja frente ao golpe de março de 1976 e em sua caracterização; nas primeiras reações da Igreja e as razões de sua adesão; no posicionamento do episcopado frente ao regime militar desde os apoios entusiasmados e nas adesões pragmáticas às débeis oposiçōes. Nos três capítulos que se seguem Obregon enfatiza as relaçóes entre Forças Armadas e Igreja a partir da análise do lugar que a mesma ocupa na estratégia de legitimação construída pelo novo regime; dos papéis do integrismo católico no interior das Forças Armadas, instrumentalizado pela tese da 'infiltração marxista' no seio da Igreja, e do desempenho do clero castrense e das capelanias militares na repressão política. Ao longo do texto ele problematiza o posicionamento da Igreja, das Forças Armadas, e a luta pelos direitos humanos. Para ele, trata-se de um dilema em que o episcopado vai se colocar diante de uma encruzilhada. Este dilema aparece com visibilidade na Assembléia Geral do Episcopado Argentino realizada em maio de 1976, como conseqüência do terror que se abatia sobre a chamada 'Igreja del pueblo' e do silêncio da hierarquia eclesiástica. Desvela a reação do Vaticano diante da quebra da autonomia da Igreja frente às intervenções das Forças Armadas em questôes doutrinárias e como tudo isto foi incorporado ou não aos documentos episcopais. Analisa ainda a reação dos militares e do episcopado diante dos organismos de direitos humanos.

Obregon termina o livro abordando as tensões e debates no campo católico sobre questôes relativas à unidade da ortodoxia e institucional, partindo dos pressupostos da política de disciplinamento adotada pela hierarquia, que visava o isolamento da pastoral popular. Em suas conclusões, o autor expõe as bases históricas da aliança conservadora construída entre a cruz e a espada. Para ele tratou-se da emergência de um velho mito expresso pela 'Argentina católica'; diante do 'estado de excepción' e da 'campanha antiargentina', teoricamente protagonizada por 'apátridas' que, do exterior, denunciavam as atrocidades do regime. $\mathrm{O}$ autor aborda 
ainda a difícil operação discursiva construída pelo episcopado segundo a qual 'El Processo' era uma barreira contra a dessacralização e a crise moral que havia se abatido sobre a Argentina e consistia de uma cruzada anticomunista que unia a Igreja e as Forças Armadas na busca do disciplinamento daquela sociedade.

Em síntese, Obregon trata do posicionamento da instituição, mais especificamente da sua cúpula, e não somente de alguns dos seus setores, e, ao mesmo tempo, procura problematizar os diferentes debates ocorridos no seio do episcopado, terminando por evidenciar que, apesar das diversas contradições existentes, esta instituição se colocou formalmente ao lado do regime.

É importante ressaltar que uma das grandes dificuldades para a realização de pesquisas sobre a atuação da Igreja Católica tem sido o acesso aos seus arquivos, já que esta instituição não prima pela transparência de seus atos e muito menos pelo cuidado e disponibilização dos seus acervos documentais. $\mathrm{O}$ fato de haver muitas interdiçôes à pesquisa histórica não significa que esta seja impossível. É exatamente o que demonstra Martín Obregon, que ao elaborar seu trabalho se utiliza da documentação acumulada pela
Conferência Episcopal Argentina, particularmente aquelas produzidas por algumas comissóes e pelas Assembléias Gerais; do Boletim da Agência Informativa Católica Argentina - AICA -, editado sob a responsabilidade do arcebispado de Buenos Aires, produzido quinzenalmente e que reproduzia os eventos ocorridos no meio católico.

Além destas fontes, o autor também consultou publicações católicas, em especial a revista Critério que, desde os tempos do Concilio Vaticano II, sintetizava as posiçóes dos setores renovadores do catolicismo argentino, os jornais $L a$ Nación, Clarín, La Prensa e, evidentemente, a bibliografia existente sobre o período histórico em questão.

Do ponto de vista metodológico, Obregon situa seu trabalho no campo da história das idéias, embora conceda uma centralidade na descrição dos acontecimentos por julgar importante a reconstrução do cenário que ainda lhe parece fragmentada. Busca demonstrar a existência de substrato ideológico comum entre a Igreja e as Forças Armadas, construído ao longo do século XX. Tenta, sobretudo, articular duas dimensões: aquela referida a um conjunto de questôes voltadas para a vida interna da Igreja enquanto 
instituição eclesial, e a situação política da Argentina naquele período histórico onde a Igreja era considerada como fator político importante.

Obregon ressalta a escassez bibliográfica sobre o tema em pauta, ainda que reconheça a multiplicação dos trabalhos de investigação sobre a emergência e natureza do regime implantado após março de 1986, e realiza um atualizado balanço historiográfico sobre o papel da Igreja Católica na história política da Argentina.

A estratégia narrativa de Verbitsky está centrada na trajetória do cardeal Bergoglio e em como esta se articula com a aliança que o episcopado castrense faz, desde os anos de 1950, com a chegada em Buenos Aires de La Cite Catholique, criada por Jean Ousset; esta, por sua vez, era um retorno de L'Action Française fundada por Charles Maurras, com a doutrina da contra-revolução, a técnica da tortura e seu fundamento tomista. De certa forma, ele retoma a trajetória da Igreja argentina analisando o seu alinhamento, ao longo da segunda metade do século XX, com os setores da direita mundial.

É uma investigação jornalística que se inicia desvendando o cenário no qual a Comissão Interamericana de Direitos Humanos visitou a Escuela de Mecánica de la Armada - ESMA - em 1979 e não encontrou nem mesmo os rastros dos prisioneiros que ali estavam. Todos se perguntaram para onde eles haviam sido levados.

A investigação do autor em tela responde: com a ajuda do núncio apostólico Pio Laghi e do secretário do Vicariato castrense, Emilio Grasselli, foram levados para a ilha de El Silencio, propriedade da Igreja Católica argentina e lugar de lazer do cardeal primaz de Buenos Aires, Dom Jorge Bergoglio.

Esta ilha, descrita por Sarmiento como "la más caprichosa e indescriptible', em que "la superfície es una ilusión, no es tierra toda a que parece ni puede saberse de antemano lo que existe útil”, está localizada no delta do rio Paraná.

A 'transferência' foi realizada em nome de um chamado programa de reeducação dos prisioneiros da ESMA. A investigação mostra ainda a sedução que o Almirante Massera, comandante da Marinha, exercia sobre o papa Paulo VI no jogo duplo montado pelo cardeal primaz. É um trabalho revelador das relações estabelecidas entre a Igreja Católica Argentina, notadamente dos setores castrenses, e os poróes da ditadura. 
O livro foi escrito a partir de pesquisas realizadas nos arquivos das Cámaras Federales da capital e de La Plata, ao Archivo de la Cancillería, dos arquivos do jornal El Clarín, de documentados acumulados pelo centro de documentação do Centro de Estudios Legales y Sociales, do National Security Archives de Washington e de entrevistas realizadas com dezenas de vítimas. Contou ainda com a colaboração de pesquisadores da Asemblea permanente del Juicio por la Verdad e de outros pesquisadores em toda a América Latina.

É um relato dramático, desta viagem ao desconhecido e do cotidiano dos últimos seqüestrados que, em setembro de 1979, "le quedaban a grupo de tareas de la Escuela sede Mecânica de la Armada".

As duas obras são referências importantes para o estudo do papel político desempenhado pela Igreja na América Latina, além de indicar as variadas e instigantes possibilidades de explorar as relações entre a Igreja católica na Argentina e as Forças Armadas no período da ditadura militar. 